Case Report

\section{Meckel Gruber Syndrome: A rare and lethal anomaly}

\section{Žana Žegarac ${ }^{1 *}$, Željko Duićc ${ }^{1,2}$ and Katarina Bojanić ${ }^{3}$}

'Department of Obstetrics and Gynecology, Merkur University Hospital, Zagreb, Croatia

${ }^{2}$ School of Medicine Univeristy of Zagreb, Zagreb, Croatia

${ }^{3}$ Division of Neonatology, Department of Obstetrics and Gynecology, Merkur University Hospital,

Zagreb, Croatia

\section{Dear Editor,}

We wish to present our case of the rare Meckel-Gruber syndrome, diagnosed prenatally at 18 weeks' gestation. Informed consent was obtained from both parents for publishing this case and including photos.

Meckel-Gruber syndrome (MGS) is an autosomal recessive disorder characterized by at least two of the following three manifestations; renal cystic dysplasia (95\%-100\%), occipital encephalocele (60\%-80\%) and postaxial polydactyly (55\%-75\%) [1]. Other anomalies of MGS include a variety of CNS malformations such as microcephaly, anencephaly, holoprosencephaly, hydrocephaly, Arnold-Chiari or Dandy Walker malformation, agenesis of the corpus callosum, absence of olfactory tract or lobe and cardiac anomalies atrial septal defect, ventricular septal defect [2]. The excessively large, cystic kidneys cause marked abdominal distension. Facial anomalies such as cleft lip, high arched palate and hypertelorism are also observed in many cases [2].

Ultrasound examination at 18 weeks' gestation of a 36-yearold gravida 7, para 6 mother revealed a single intrauterine pregnancy with multiple fetal malformations attributable to Meckel Gruber syndrome: occipital encephalocoele (partial

\section{More Information}

*Address for Correspondence: Žana Žegarac, Department of Obstetrics and Gynecology, Merkur University Hospital, Zajčeva 19, 10000 Zagreb, Croatia, Tel; 00385914776595; Email: zanazegarac@yahoo.com

Submitted: 09 November 2019 Approved: 05 December 2019 Published: 06 December 2019

How to cite this article: Žegarac Ž, Duić Ž, Bojanić K. Meckel Gruber Syndrome: A rare and lethal anomaly. Clin J Obstet Gynaecol. 2019; 2: 133-134.

DOI: dx.doi.org/10.29328/journal.cjog.1001035

Copyright: @ 2019 Žegarac Ž, et al. This is an open access article distributed under the Creative Commons Attribution License, which permits unrestricted use, distribution, and reproduction in any medium, provided the original work is properly cited.

(W) Check for updates

absence of the occipital bone with prolapsing meninges 33 x $34 \mathrm{~mm}$ in size), a "lemon sign" appearance of the scull, choroid plexus cyst, cerebellar vermis agenesis and venticulomegaly. Fetal kidneys were enlarged, spongy and polycystic, measuring $30 \times 17 \mathrm{~mm}$ with oligohydramnios. Early amniocentesis revealed a normal karyotype, $46 \mathrm{XX}$. The mother did not resolve to terminate the pregnancy. She had three healthy children. Her past obstetric history revealed two spontaneous abortions at 7 and 12 weeks' gestation and one induced medical abortion at 21 weeks' gestation due to multiple fetal malformations (ventriculomegaly and polycistic kidneys with normal karyotype 46, XX).

A 3210 gram female infant was born via spontaneous vaginal delivery at 39 weeks' gestation. Apgar scores were 5
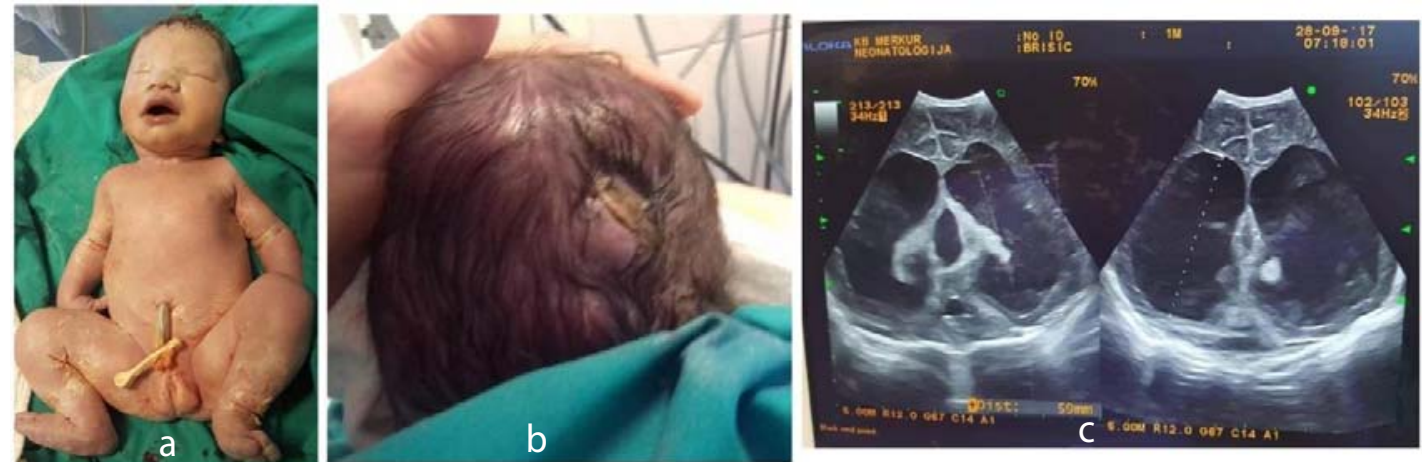

Figure 1: a) Our newborn female patient with MGS. b) Occipital encephalocele in our patient. c) Head ultrasonography following birth showed ventriculomegaly with reduced brain tissue. 
and 5 at 1 and 5 minutes respectively (Figure 1a). An occipital encephalocele measuring $20 \times 20 \mathrm{~mm}$ (Figure 1b) was present. Brain ultrasound showed ventriculomegaly $59 \mathrm{~mm}$ in diametar with significantly reduced brain tissue (Figure 1c). Neonatal kidneys were large, polycystic and spongy. Palliative care was given and the neonate died 2 hours following birth. Autopsy was not done due to the parents' request. Diagnosis of MGS was based on prenatal and postnatal findings.

The first report of MGS was published in 1822 by Johann Friedrich Meckel. The prevelance varies from 1 per 1300 to 1 per 140000 live births [1]. The highest incidence was reported in Gujarati Indians 1 per 1300 [3] and Finland9000 [4]. A population based study of Meckel-Gruber syndrome in Europe from 1990 to 2011 reported a mean prevalence of 2.6 per 100000 births and did not report any cases in Croatia [5]. MGS is known to be a heterogeneous disease and can be caused by pathogenic variants in one of the following genes: MKS1, TMEM216, TMEM67, CEP290, RPGRIP1L, CC2D2A, NPHP3, TCTN2, B9D1, B9D2, and TMEM231. These genes encode proteins which play a role in the structure and function of cilia. Cilia are important for the structure and function of many types of cells, including brain, kidney and liver cells. Defects in these cell structures disrupt important chemical signalling pathways during early development [5]. MGS is usually diagnosed with ultrasonography in second trimesterpregnancy. Characteristic findings include occipital encephalocele, polycystic kidneys and post axial polydactyly [3]. The mean gestation age at diagnosis is 14 weeks [5]. Prenatal detection rate of major anomalies characteristic of MGS by prenatal ultrasound examination was 93,4\% [5]. Differential diagnosis of MGS include: trisomy 13, Larsen syndrome, Smith-Lemli-Opitz syndrome and Bardet-Biedl syndrome [2]. MGS is a lethal disorder. Most infants are stillborn or die within a few hours or days following birth. The longest known survivor lived 4 months [1]. As MGS has a high risk (25\%) of recurrence, genetic couseling should be provided [2]. Early diagnosis is important for the timely consultation of affected couples regarding their decision of pregnancy termination.

\section{References}

1. Roy J, Pal M. Meckel gruber syndrome. J Clin Diagn Res. 2013; 7: 21022103.

PubMed: https://www.ncbi.nlm.nih.gov/pmc/articles/PMC3809697/

2. Khurana S, Saini V, Wadhwa V, Kaur H. Meckel-Gruber syndrome: ultrasonographic and fetal autopsy correlation. J Ultrasound. 2017; 4; 20: $167-170$

PubMed: https://www.ncbi.nlm.nih.gov/pubmed/28593008

3. Parelkar SV, Kapadnis SP, Sanghvi BV, Joshi PB, Mundada D, et al. Meckel-Gruber syndrome: A rare and lethal anomaly with review of literature. J PediatrNeurosci. 2013; 8: 154-157.

PubMed: https://www.ncbi.nlm.nih.gov/pmc/articles/PMC3783728/

4. Aslan K, Külahçı Aslan E, Orhan A, Atalay MA. Meckel Gruber syndrome, A case report. Organogenesis. 2015; 11: 87-92.

PubMed: https://www.ncbi.nlm.nih.gov/pmc/articles/PMC4594365/

5. Barisic I, Boban L, Loane M, Garne E, Wellesley D, et al. MeckelGruber Syndrome: a population-based study on prevalence, prenatal diagnosis, clinical features, and survival in Europe. Eur J Hum Genet. 2015; 23: 746-752.

PubMed: https://www.ncbi.nlm.nih.gov/pmc/articles/PMC4795048/ 